\title{
Insulin resistance without obesity induced by cotton pellet granuloma in mice
}

\author{
Hung-Tsung $\mathrm{Wu}^{1,2}$, Cheng Kuei Chang ${ }^{3}$, Chiung-Wen Tsao ${ }^{4}$, Ya-Ju Wen², Sheng-Ming Ling ${ }^{2}$, Kai-Chun Cheng ${ }^{2}$, \\ Chi-Jean Chang ${ }^{5}$ and Juei-Tang Cheng ${ }^{1,2}$
}

Obesity leads to insulin resistance because the larger adipocytes in obese persons secrete proinflammatory cytokines that cause chronic inflammation in adipose tissue. This, in turn, leads to the alteration of adipokine secretion, which can induce insulin resistance. However, the development of insulin resistance without obesity is still obscure. We aimed to use an animal inflammation model with cotton pellet granuloma (CPG) in adipose tissue to characterize insulin resistance formation. We found that CPG in epididymal white adipose tissue (WAT), rather than in interscapular brown adipose tissue, impaired insulin sensitivity, and glucose utilization, and that it decreased levels of phosphoinsulin receptor and phospho-Akt in both muscle and liver tissue, but that it did not modify the body weight or food intake in mice.

Macrophage infiltration in adipose tissue, leukocyte counts, monocyte chemoattractant protein-1, and interleukin-6 were elevated in CPG-treated mice. However, we found a marked decrease of plasma adiponectin only in the WAT group, which might have been because of the lower level of peroxisome proliferator-activated receptor- $\gamma$ in WAT. These results show that granuloma formation in WAT by implantation of a cotton pellet may induce insulin resistance under nonobese condition through circulating inflammatory mediators, especially the low level of adiponectin.

Laboratory Investigation (2009) 89, 362-369; doi:10.1038/labinvest.2008.161; published online 12 January 2009

KEYWORDS: adipose tissue; adiponectin; cotton pellet granuloma; insulin resistance; inflammation

Obesity is a key factor in type 2 diabetes $^{1}$ and it inflames visceral white adipose tissue (WAT) ${ }^{2}$ to secrete adipokines that activate resident macrophages, which, in turn, secrete chemokines that recruit additional monocytes into fat. ${ }^{3,4}$ Adipokines modulate immune responses and promote vascular dysfunction ${ }^{5}$ or insulin resistance ${ }^{6}$ in an endocrine, autocrine, or paracrine manner. Low-grade systemic inflammation is thought to be linked to the development of insulin resistance; ${ }^{3,7,8}$ inflammation in adipose tissue alters the levels of adipokines in circulation.,

Several proinflammatory factors, such as tumor necrosis factor- $\alpha$ (TNF- $\alpha$ ), MCP-1, and IL-6, are also adipokines that directly affect insulin signaling ${ }^{9,10}$ and regulate homeostatic systems and insulin sensitivity. ${ }^{3}$ Systemic inflammation diseases such as rheumatoid arthritis induce insulin resistance. ${ }^{11}$ As in obesity, circulating levels of TNF- $\alpha$ and IL- 6 are elevated in patients with rheumatoid arthritis. However, body weight and body mass index are normal in most patients with rheumatoid arthritis. ${ }^{12}$ This raises a question about whether obesity is involved in the development of insulin resistance under inflammatory condition.

Responses to foreign bodies include macrophage adhesion as well as increased cytokine release and neovascularization. ${ }^{13}$ In this study, we used the cotton pellet granuloma (CPG) method, which is extensively used to estimate antiinflammatory activity, ${ }^{14,15}$ as the foreign body implantation model to evaluate the development of insulin resistance.

\section{MATERIALS AND METHODS \\ Animals}

Twelve-week-old BALB/c male mice were purchased from the Animal Center of National Cheng Kung University Medical College. Mice were housed in a temperature $\left(25 \pm 1^{\circ} \mathrm{C}\right)$ and humidity $(60 \pm 5 \%)$ controlled room and kept on a 12:12

\footnotetext{
${ }^{1}$ Institute of Basic Medical Sciences, College of Medicine, National Cheng Kung University, Tainan City, Taiwan; ${ }^{2}$ Department of Pharmacology, College of Medicine, National Cheng Kung University, Tainan City, Taiwan; ${ }^{3}$ Department of Surgery, Mackay Memorial Hospital, Graduate Institute of Injury Prevention and Control, Taipei Medical University, Taipei City, Taiwan; ${ }^{4}$ Department of Nursing, Chung Hwa University of Medical Technology, Tainan County, Taiwan and ${ }^{5}$ Department of Family Medicine, College of Medicine, National Cheng Kung University, Tainan City, Taiwan

Correspondence: Professor J-T Cheng, PhD, Department of Pharmacology, College of Medicine, National Cheng Kung University, Number 1 University Road, Tainan 70101, Taiwan.
}

E-mail: jtcheng@mail.ncku.edu.tw

Received 4 May 2008; revised 18 September 2008; accepted 27 September 2008 
light-dark cycle (light on at 0600). The animal procedures were performed according to the Guide for the Care and Use of Laboratory Animals of the National Institutes of Health, as well as the guidelines of the Animal Welfare Act.

\section{Cotton Pellet Granuloma Model}

All mice were anesthetized intraperitoneally (i.p.) with $10 \mathrm{mg} / \mathrm{kg}$ of pentobarbital. The sterilized cotton pellets, weighing $10 \pm 1 \mathrm{mg}$ each, were implanted on two sides of the epididymal WAT group or interscapular brown adipose tissue (BAT group). Body weight and food intake for each mouse were recorded for the following 7 days, and then all the mice were killed. The serum from each group was collected for enzyme-linked immunosorbent assays (ELISA) before the livers, skeletal muscle, WAT and BAT were collected and stored for further experiments.

\section{Tolbutamide Test Assay}

Each group of mice was given tolbutamide $(10 \mathrm{mg} / \mathrm{kg}$; i.p.; Sigma-Aldrich, St Louis, MO, USA), and their blood glucose levels were determined after $90 \mathrm{~min}$ using an automatic blood glucose meter (Quik-Lab, Ames; Miles Inc., Elkhart, IN, USA) as previously described. ${ }^{16}$

\section{Insulin Tolerance Test}

The mice were fasted for $6 \mathrm{~h}$ and then their insulin tolerance was tested and initial blood glucose was determined. The mice were next given insulin $(1.0 \mathrm{mU} / \mathrm{g}$; i.p.; Novo Nordisk, Bagsvaerd, Denmark), and the blood samples were collected from the retroorbital sinus of each mouse at $0,30,60,90$, and 120 min postinjection for blood glucose measurements.

\section{Intraperitoneal Glucose Tolerance Test}

The mice were fasted for $6 \mathrm{~h}$ and then given glucose $(1.0 \mathrm{~g} / \mathrm{kg}$; i.p.). Blood samples were collected from the retroorbital sinus at regular intervals, and then the glucose concentration was measured.

\section{Western Blot Analysis}

After starvation for $24 \mathrm{~h}$, the mice were given 5 units of insulin (Novo Nordisk) in the inferior vena cava. After $5 \mathrm{~min}$, the liver and hind leg muscles were removed, and the samples were homogenized with ice-cold phosphate-buffered saline (PBS) containing $1 \%$ Nonidet P-40, $1 \mathrm{mM}$ of phenylmethylsulfonyl fluoride, $10 \mu \mathrm{g} / \mathrm{ml}$ of aprotinin, $50 \mathrm{mM}$ of sodium fluoride, and $2 \mathrm{mM}$ of sodium orthovanadate (Sigma-Aldrich). Protein lysates $(30 \mu \mathrm{g})$ were separated using $10 \%$ SDS-polyacrylamide gel electrophoresis and transferred to a polyvinylidene difluoride membrane (Millipore, Billerica, MA, USA). After they had been blocked with 3\% milk in TBS-T (10 mM Tris (pH 7.6), $150 \mathrm{mM} \mathrm{NaCl}$, and $0.05 \%$ Tween 20), the membranes were incubated with appropriate antibodies containing insulin receptor (IR; Neomarkers, Fremont, CA, USA), phospho-IR Tyr972 (Upstate Biotechnology, Temecula, CA, USA), Akt and phospho-Akt (Cell
Signaling Technology, Beverly, MA, USA), peroxisome proliferator activator receptor- $\gamma$ (PPAR $\gamma$; Santa Cruz Biotechnology, Santa Cruz, CA, USA). Subsequently, the blots were visualized using an enhanced chemiluminescence kit (PerkinElmer, Boston, MA, USA). Actin (Sigma-Aldrich) was an internal control. The optical densities of the bands were determined using software (Gel-Pro Analyzer 4.0; Media Cybernetics Inc., Silver Spring, MD, USA).

\section{Histological Analysis}

The WAT and BAT were removed from each group of mice, fixed in PBS containing 10\% formaldehyde, and maintained at $4{ }^{\circ} \mathrm{C}$ for 2 days. Fixed specimens were dehydrated and embedded in paraffin. The fat pad was then cut into $5-\mu \mathrm{m}$ thick sections at 50- $\mu \mathrm{m}$ intervals and then stained with hematoxylin and eosin (H\&E). For macrophage staining, the samples were mounted on glass slides and depleted of paraffin with xylene, and autoclave $\left(121^{\circ} \mathrm{C}, 1.1 \mathrm{~atm}\right.$ for $\left.16 \mathrm{~min}\right)$ in $0.01 \mathrm{M}$ sodium citrate buffer ( $\mathrm{pH}$ 6.0). After they had been blocked with 5\% milk, the sections were immunohistochemically stained overnight at $4^{\circ} \mathrm{C}$ with a 1:1000 dilution of F4/80 antibody (Serotec, Oxford, UK). Immune complexes were detected with biotinylated secondary antibodies (BD Biosciences, San Diego, CA, USA), HRP-conjugated streptavidin (Dako, Kyoto, Japan), and the peroxidase substrate diaminobenzidine (Dako). After they had been counterstained with hematoxylin (Muto Pure Chemicals, Tokyo, Japan), mounting solution (Matsunami Glass, Osaka, Japan), and cover slips were added to the sections. The sections were then observed with a light microscope.

\section{Flow Cytometry}

The tissue was cut into small pieces and digested for $40 \mathrm{~min}$ at $37^{\circ} \mathrm{C}$ with $2 \mathrm{mg} / \mathrm{ml}$ of type-II collagenase (Sigma-Aldrich) in Krebs Ringer bicarbonate buffer ( $\mathrm{pH}$ 7.4). After it had been digested, the fraction of the digested tissue was filtered through a nylon mesh $(100 \mu \mathrm{m})$, the filtrate was centrifuged at $200 \mathrm{~g}$. The stromal-vascular fraction was obtained from the resulting pellet. Red blood cells were removed using lysis buffer containing $155 \mathrm{mM}$ of ammonium chloride (SigmaAldrich), $10 \mathrm{mM}$ of potassium bicarbonate (Fisher Biotech, Pittsburgh, PA, USA), 0.5 M EDTA ( $\mathrm{pH} 8.0$ ), and $1 \mathrm{~N}$ hydrochloric acid. The remnant was suspended and fixed in PBS containing 4\% paraformaldehyde for $2 \mathrm{~h}$. The cells were then labeled with FITC-conjugated antibodies to mouse F4/ 80 (Serotec), Gr-1, and CD31 (BD Biosciences). Each cell population was then quantitated (FACScan; BD Biosciences).

\section{Analyzing Parameters in Serum}

ELISA kits were used to determine MCP-1 (eBioscience, San Diego, CA, USA), IL-6, resistin (AssayPro, Brooklyn, NY, USA), insulin (Mercodia AB, Uppsala, Sweden), and adiponectin (R\&D Systems, Minneapolis, MI, USA) levels in serum. Homeostasis model assessment-insulin resistance 
(HOMA-IR) was calculated as fasting glucose $(\mathrm{mM}) \times$ fasting insulin $(\mathrm{mU} / \mathrm{l}) / 22.5 .^{17}$ Blood smear specimens were made and stained with Wright-Giemsa stain for white blood cell counts.

\section{Statistical Analysis}

All data are mean \pm s.e.m. The differences between the WAT, BAT, and sham groups were compared using Student's $t$-test. Statistical significance was set at $P<0.05$.

\section{RESULTS}

\section{Cotton Pellet Implantation Induced CPG Formation without Obesity}

Cotton pellets were implanted into the WAT and interscapular BAT of mice for 7 days, at which point they developed CPG (Figure 1a). There were no statistically significant differences in body weight, food intake, or blood glucose levels between the cotton-implanted WAT and BAT groups and the sham group (Table 1).
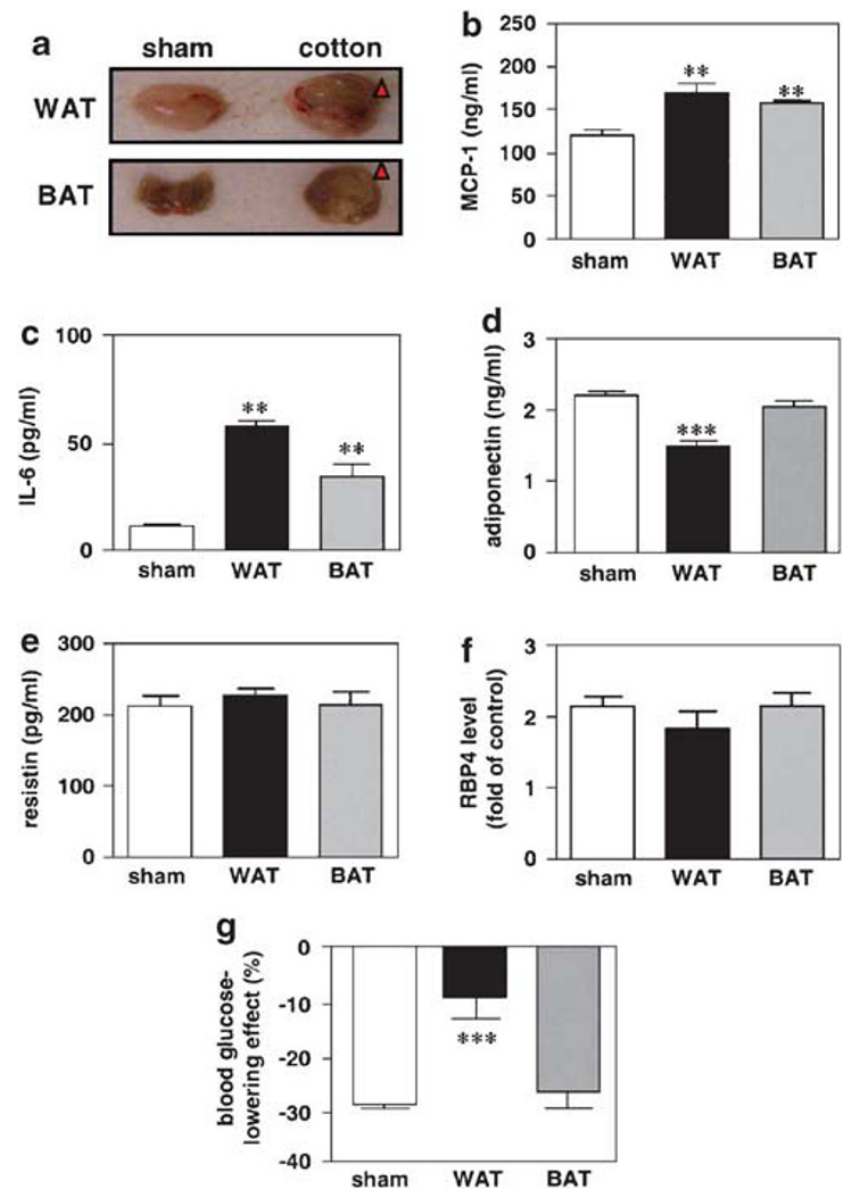

Figure 1 Cotton pellets implanted in the epididymal white adipose tissue (WAT) and interscapular brown adipose tissue (BAT) of BALB/c male mice. After pellet implantation for 7 days, granuloma formation (a), altered proinflammatory cytokine levels (b-f), and decreased sensitivity to tolbutamide (g) were observed. Data are mean ( \pm s.e.m.) of the averages from six to eight experiments. ${ }^{*} P<0.05,{ }^{* *} P<0.01$, and ${ }^{* * *} P<0.001$ compared with the sham group.

\section{Changes of Plasma Leukocyte Counts and Proinflammatory Cytokines in CPG-Treated Mice}

Both the WAT and BAT groups showed significant increases in total white blood cells, neutrophils, and mononuclear cells (Table 1; $P<0.05-0.001$ ), in addition to higher levels of the MCP-1 (Figure 1b) and IL-6 (Figure 1c; $P<0.01$ ). The adiponectin level was significantly lower in the WAT group but not in the BAT group compared with the sham group (Figure 1d; $P<0.001$ ). Resistin (Figure 1e) and RBP4 (Figure 1f) levels were not significantly different between the three groups.

\section{Mice Decreased Their Response to Tolbutamide after Implanting Cotton Pellets in WAT Group}

The response of WAT group mice to tolbutamide, an insulinreleasing agent, was significantly decreased compared with the sham group (9.6 vs 30.7\%; Figure 1g; $P<0.001$ ). The reduction of the blood glucose-lowering action of tolbutamide in the WAT group reached the maximum on day 7 and declined on day 21 (data not shown). There was no significant difference between the BAT and sham groups.

\section{Implanting Cotton Pellets in WAT Group Mice Induced} Insulin Resistance and Glucose Intolerance

An intraperitoneal glucose tolerance test and insulin tolerance test were used to assess insulin sensitivity showed that the blood glucose-lowering action of insulin (Figure 2a) and the glucose utilization (Figure 2b) of the WAT group, but not of the BAT group, were impaired compared with the sham group.

\section{Implanting Cotton Pellets in WAT Group Mice Decreased Phosphorylation of IR and Akt Proteins in Their Skeletal Muscle and Liver Tissue}

To confirm that implanting cotton pellets in WAT group mice caused the defects in insulin signaling, western blotting was used to examine the levels of phosphorylated IR and Akt in muscle and liver tissue. The relative expression levels of the phosphoproteins were normalized to those of the proteins themselves. In the presence of insulin stimulation, the levels of phospho-IR (Figure 3a and c) and Akt (Figure 3b and d) in both muscle and liver tissue were decreased in WAT but not BAT group mice compared with the sham group.

\section{Implanting Cotton Pellets in WAT and BAT Group Mice Increased Macrophage Infiltration in Their Adipose Tissue}

After cotton had been implanted in WAT and BAT group mice for 7 days, H\&E staining showed a marked increase in mononuclear cell infiltration in WAT (Figure 4b) and BAT (Figure 4d) as compared with the sham group (Figure 4a and c). Several mononuclear cells were identified as $\mathrm{F} 4 / 80^{+}$ macrophages and the aggregated $\mathrm{F} 4 / 80^{+}$cells surrounded adipocytes in both WAT (Figure 4f) and BAT (Figure 4h) as compared with the sham group (Figure $4 \mathrm{e}$ and g). 
Table 1 Metabolic parameters between the epididymal white adipose tissue and interscapular brown adipose tissue implanted with cotton in mice

\begin{tabular}{|c|c|c|c|c|c|c|}
\hline & \multicolumn{2}{|c|}{ Sham } & \multicolumn{2}{|c|}{ WAT } & \multicolumn{2}{|c|}{ BAT } \\
\hline & Before & After & Before & After & Before & After \\
\hline Body weight (g) & $23.9 \pm 0.4$ & $24.1 \pm 0.3$ & $24.2 \pm 0.3$ & $24.0 \pm 0.4$ & $23.2 \pm 0.5$ & $23.5 \pm 0.3$ \\
\hline Food intake (g) & $5.8 \pm 0.2$ & $5.6 \pm 0.1$ & $5.6 \pm 0.4$ & $5.4 \pm 0.1$ & $5.6 \pm 0.1$ & $5.8 \pm 0.3$ \\
\hline Blood glucose (mg per $100 \mathrm{ml}$ ) & $144.4 \pm 3.1$ & $140.6 \pm 7.1$ & $138.0 \pm 7.1$ & $142.4 \pm 7.6$ & $141.6 \pm 6.7$ & $132.0 \pm 8.3$ \\
\hline HOMA-IR & $6.3 \pm 0.6$ & $6.3 \pm 0.2$ & $6.1 \pm 0.5$ & $6.9 \pm 0.2^{*}$ & $5.9 \pm 0.5$ & $6.1 \pm 0.4$ \\
\hline Total WBC $\left(10^{5}\right.$ cells per ml) & $18.0 \pm 3.0$ & $17.6 \pm 2.0$ & $19.6 \pm 2.1$ & $42.5 \pm 3.6^{* *}$ & $21.3 \pm 1.6$ & $39.8 \pm 7.0^{* *}$ \\
\hline Neutrophils ( $10^{5}$ cells per ml) & $7.4 \pm 1.8$ & $6.8 \pm 0.9$ & $6.8 \pm 1.6$ & $24.5 \pm 4.2^{* * *}$ & $6.5 \pm 1.9$ & $19.8 \pm 3.6^{* *}$ \\
\hline Mononuclear cells ( $10^{5}$ cells per $\mathrm{ml}$ ) & $11.4 \pm 4.1$ & $10.9 \pm 2.1$ & $13.9 \pm 0.4$ & $18.0 \pm 1.1^{*}$ & $15.8 \pm 0.9$ & $20.0 \pm 5.8^{* *}$ \\
\hline
\end{tabular}

${ }^{\star} P<0.05,{ }^{* *} P<0.01$, and ${ }^{* * *} P<0.001$ compared with the sham group.
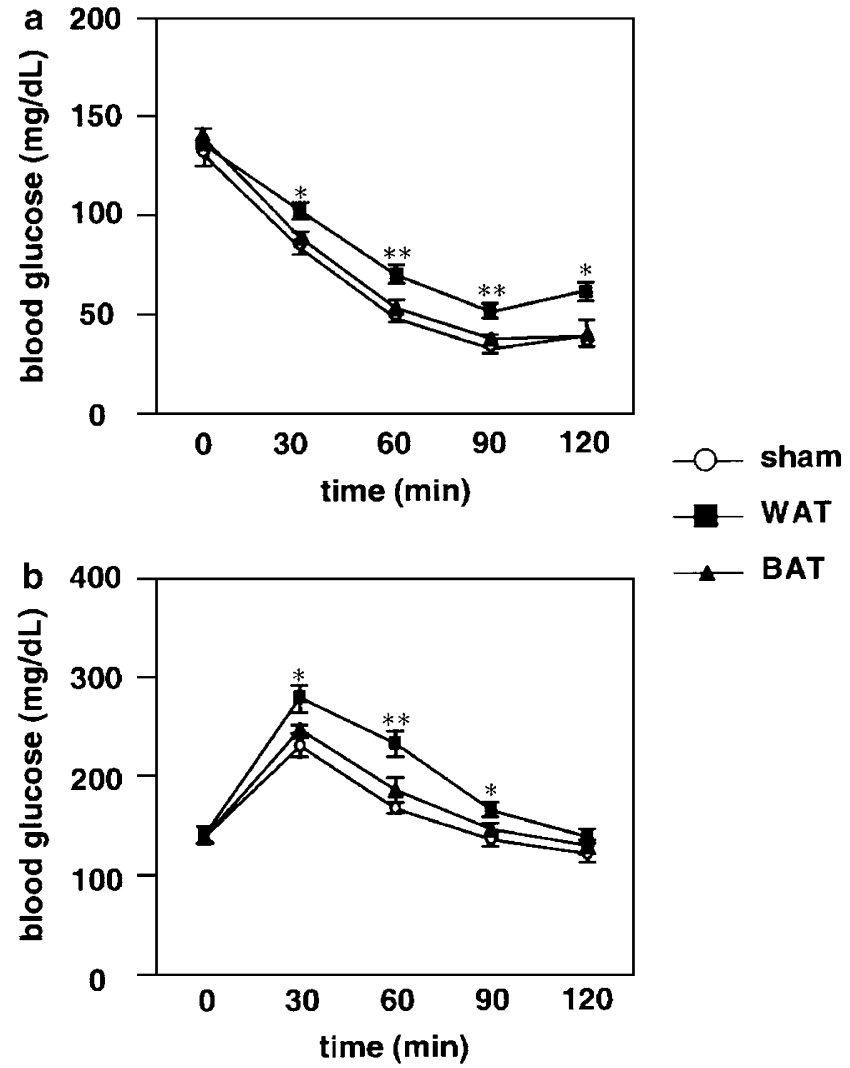

Figure 2 The epididymal white adipose tissue (WAT), but not interscapular brown adipose tissue (BAT) implanted with cotton pellet exhibits insulin resistance and glucose intolerance in mice. (a) An insulin tolerance test (ITT) and (b) an intraperitoneal glucose tolerance test (IPGTT) carried out 7 days after cotton pellets had been implanted in the epididymal WAT and interscapular BAT of BALB/C male mice showed insulin resistance and glucose intolerance in the WAT group mice. Data are mean ( \pm s.e.m.) of the averages from eight experiments. ${ }^{*} P<0.05$ and ${ }^{*} P<0.01$ compared with the sham group.

\section{Implanting Cotton Pellets in WAT Group Mice Induced Macrophage and Neutrophil Infiltration, Elevated Angiogenesis, and Decreased PPAR $\gamma$ Expression}

The degree of macrophage infiltration was quantified using flow cytometry (Figure 5a). The number of infiltrated macrophages increased 5.7 times in the stromal-vascular fraction of the WAT group compared with the sham group. The subpopulation of $\mathrm{Gr}-1^{+}$neutrophils in the WAT group was twice that of the sham group (Figure 5b). Moreover, the number of $\mathrm{CD} 31^{+}$endothelial cells increased 1.5 times in the WAT group compared with the sham group (Figure 5c). However, the level of PPAR $\gamma$ in the WAT group decreased compared with the sham group (Figure $5 \mathrm{~d}$ ).

\section{DISCUSSION}

In this study, leukocyte counts were increased after cotton implantation, moreover, the increment of inflammatory parameters, such as MCP-1 and IL-6 were also observed. These results were consistent with previous studies, ${ }^{15,18-20}$ as well as similar to the chronic inflammatory responses induced by foreign body implantation, which had enlarged population of mononuclear cells during 2 weeks. ${ }^{15,18-20}$ However, CPG did not affect body weight or food intake in WAT and BAT group mice. In addition, CPG in WAT group mice, but not in BAT group mice, impaired insulin sensitivity and glucose utility, as indicated by the exacerbated values of HOMA-IR, and that it downregulated insulin signals, as indicated by decreased levels of phospho-IR and -Akt in both muscle and liver tissue.

Neutrophils and monocytes are mentioned as a potential source of proinflammatory cytokines involved in the development of insulin resistance. ${ }^{21}$ An increased number of neutrophils was observed in patients with type 2 diabetes ${ }^{22}$ and the neutrophils showed impaired phagocytosis. ${ }^{23}$ 
a
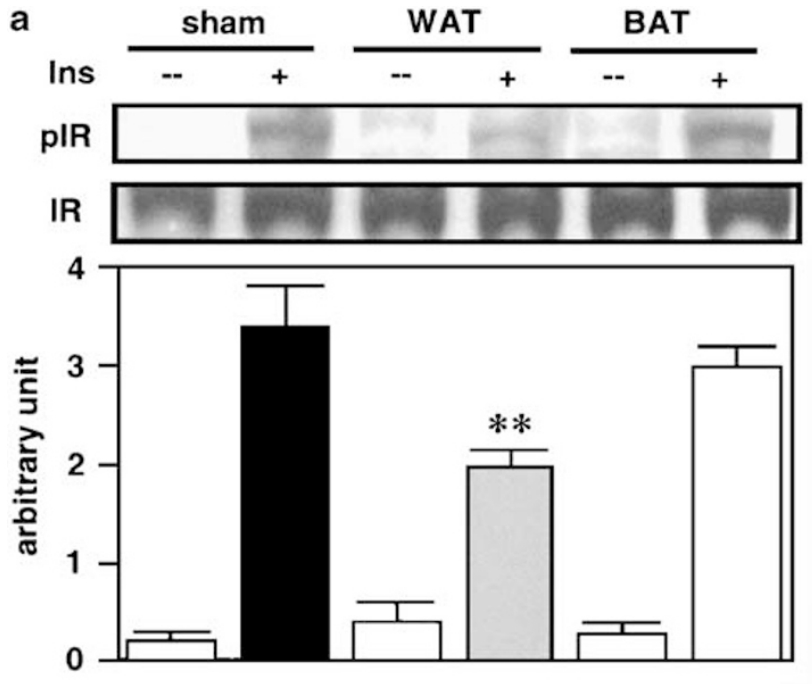

c
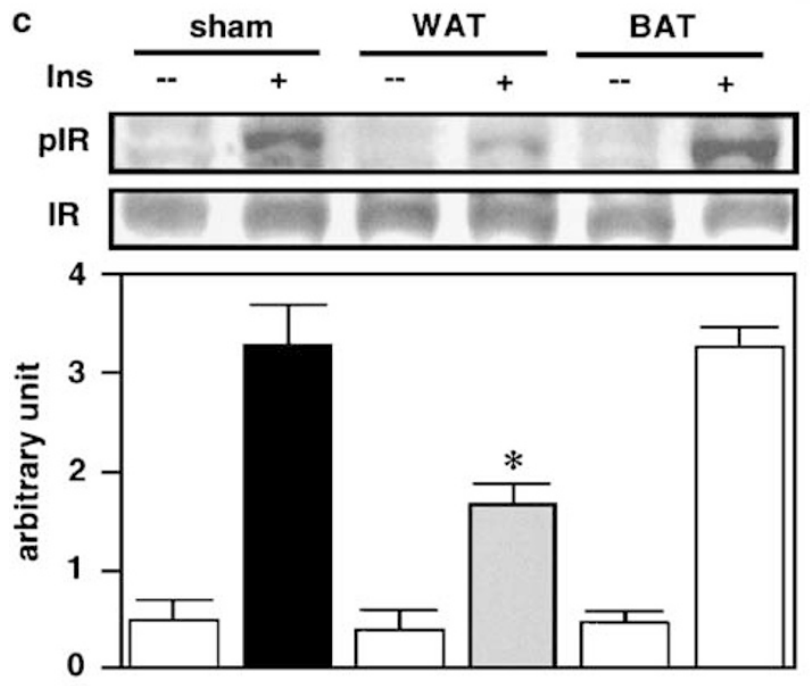

b
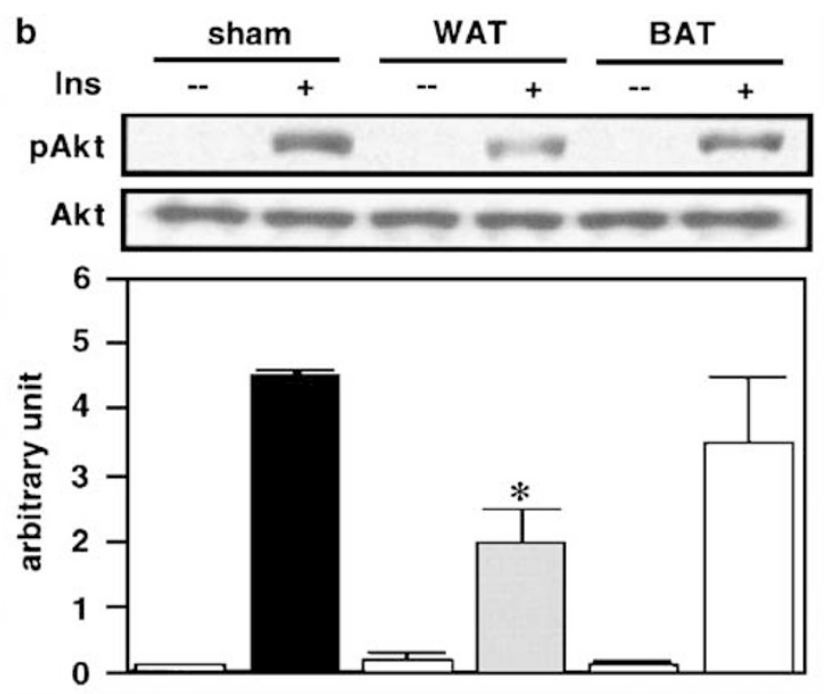

d
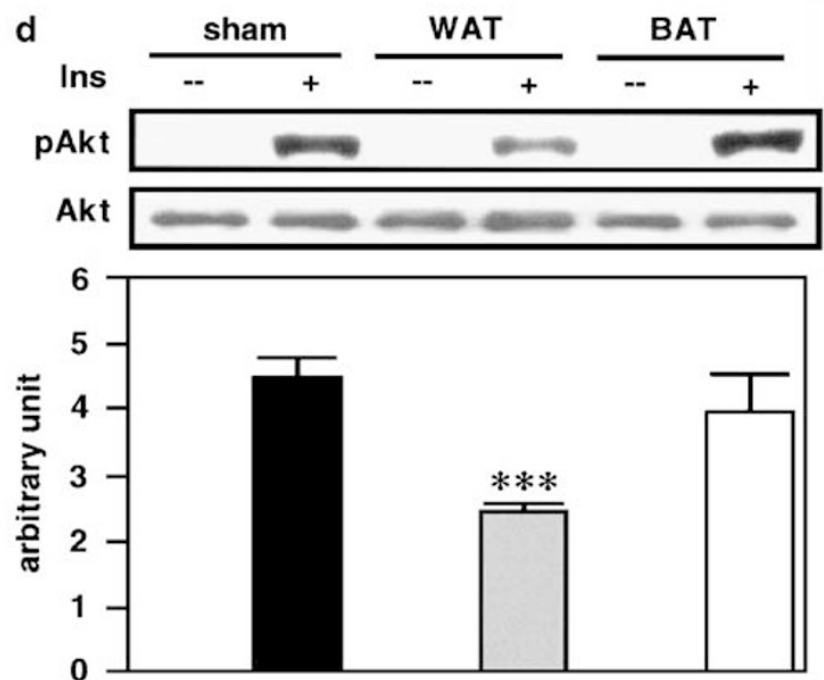

Figure 3 Decreased phosphorylation of insulin receptor (IR) and Akt proteins in skeletal muscle and liver tissue after cotton pellets had been implanted in epididymal white adipose tissue (WAT), but not interscapular brown adipose tissue (BAT). Protein expression was detected in skeletal muscle (a, b) and liver

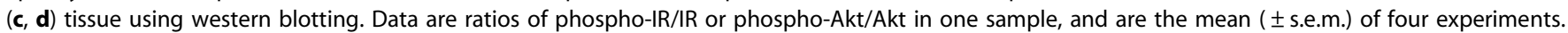
${ }^{\star} P<0.05,{ }^{* *} P<0.01$, and ${ }^{* * * P}<0.001$ compared with the sham group in the presence of insulin stimulation.

Moreover, monocytes with impaired chemotaxis ${ }^{24}$ and phagocytosis $^{25}$ are also found in diabetic patients. We found an increased subpopulation of mononuclear cells and neutrophils both in adipose tissue and in systemic circulation. RBP4 and resistin are associated with insulin resistance in mice, ${ }^{26,27}$ although their function in humans with type 2 diabetes is still controversial. ${ }^{28,29}$ We did not find any significant differences in serum levels of resistin or RBP4 between the WAT and BAT groups and the sham group. It seems possible that neither protein was involved in the development of insulin resistance of the CPG model.

We found that insulin resistance developed only in WAT group mice and not in BAT group mice, which might have been because of the variability between WAT and BAT: their developmental patterns, functions, and gene expression profiles are distinct. ${ }^{30,31}$ In mammals, BAT is abundant in the neonatal stage, but decreases shortly after birth and has been considered insignificant in adults. WAT, however, increases and disperses throughout the body as a young mammal grows to adulthood. ${ }^{30}$ BAT is important in both basal and inducible energy expenditure in the form of thermogenesis, ${ }^{32}$ whereas WAT is involved in energy storage and actively participates in regulating homeostatic systems. Because WAT is more responsive to inflammatory situations than BAT is, the WAT deposits are quantitatively more important than BAT. $^{33}$ In addition, a rising number of studies indicate that the gene profiles of WAT and BAT are different. ${ }^{31}$ Several complement factors, such as complement factor B, are more highly expressed in WAT. ${ }^{31}$ We found that implanting cotton pellets in both types of adipose tissue produced various 

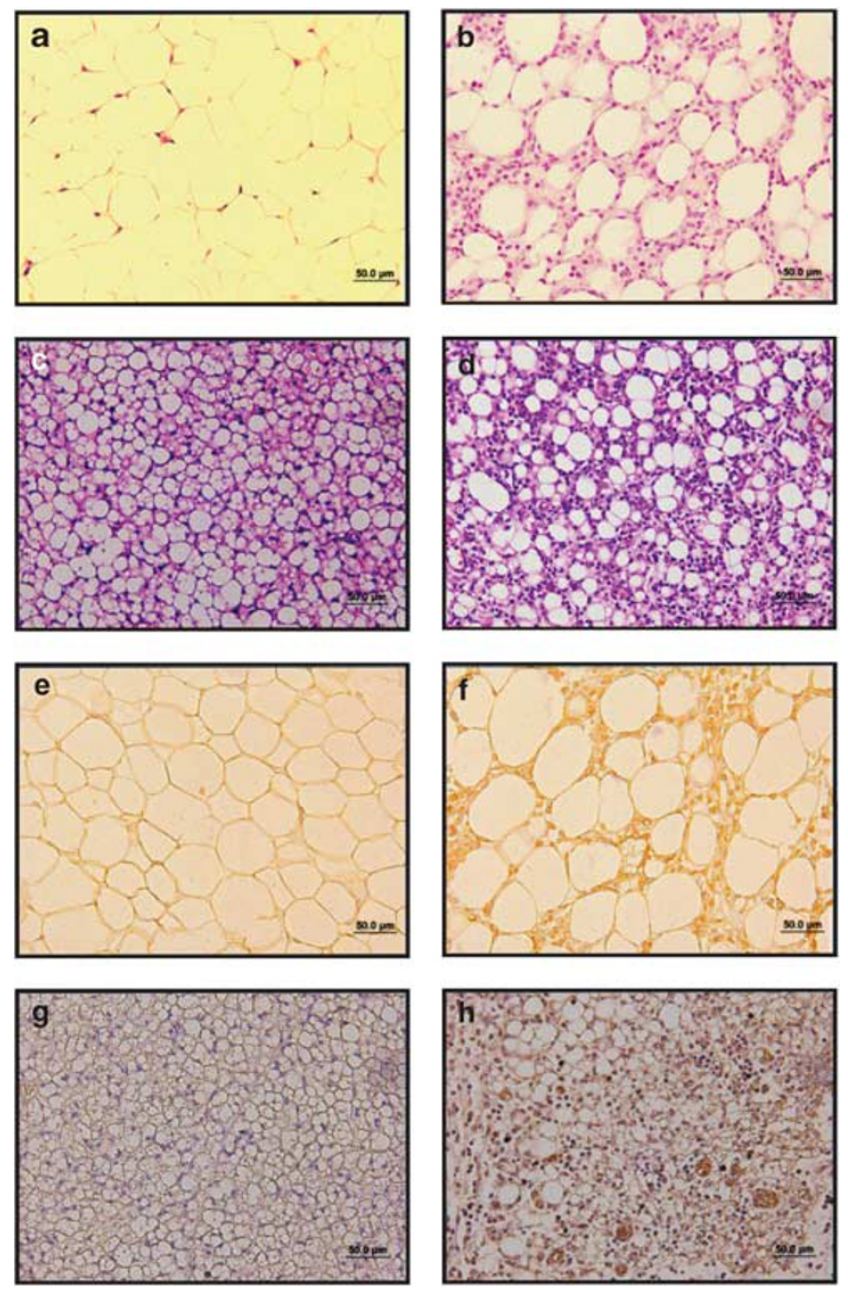

Figure 4 After cotton pellets had been implanted in the epididymal white adipose tissue (WAT) and interscapular brown adipose tissue (BAT) of BALB/C male mice, macrophage infiltration increased. The results of a histological analysis of sham $(\mathbf{a}, \mathbf{c}, \mathbf{e}, \mathbf{g})$, WAT $(\mathbf{a}, \mathbf{b}, \mathbf{e}, \mathbf{f})$, and BAT $(\mathbf{c}, \mathbf{d}, \mathbf{g}, \mathbf{h})$ group tissue are shown. Tissue sections were cut from the sham, WAT and BAT group fat pads, and then stained with hematoxylin and eosin (a-d) and F4/80 antibody (e-h).

degrees of inflammatory responses indicated by increases in the number of circulating leukocyte, in serum concentrations of MCP-1 and IL-6, and in mononuclear cell infiltration into adipose tissue. We conclude that WAT and BAT may have different functions and responses to inflammation.

Adiponectin acts in numerous ways against diabetes, inflammation, and atherogeny, ${ }^{34,35}$ and it regulates glucose metabolism as an insulin sensitizer. ${ }^{36}$ Adiponectin secreted from BAT is important for regulating glucose and lipid metabolism during the perinatal period; WAT takes over these functions and the secretion of adiponectin in adults. ${ }^{37}$ Overexpression of adiponectin in genetically obese $(\mathrm{ob} / \mathrm{ob})$ mice ameliorates insulin resistance. ${ }^{38}$ Otherwise, mice lacking adiponectin show hepatic insulin resistance. ${ }^{39}$ Moreover, a low serum level of adiponectin is thought to be a trait maker to predict the development of diabetes; ${ }^{40}$ it is also widely
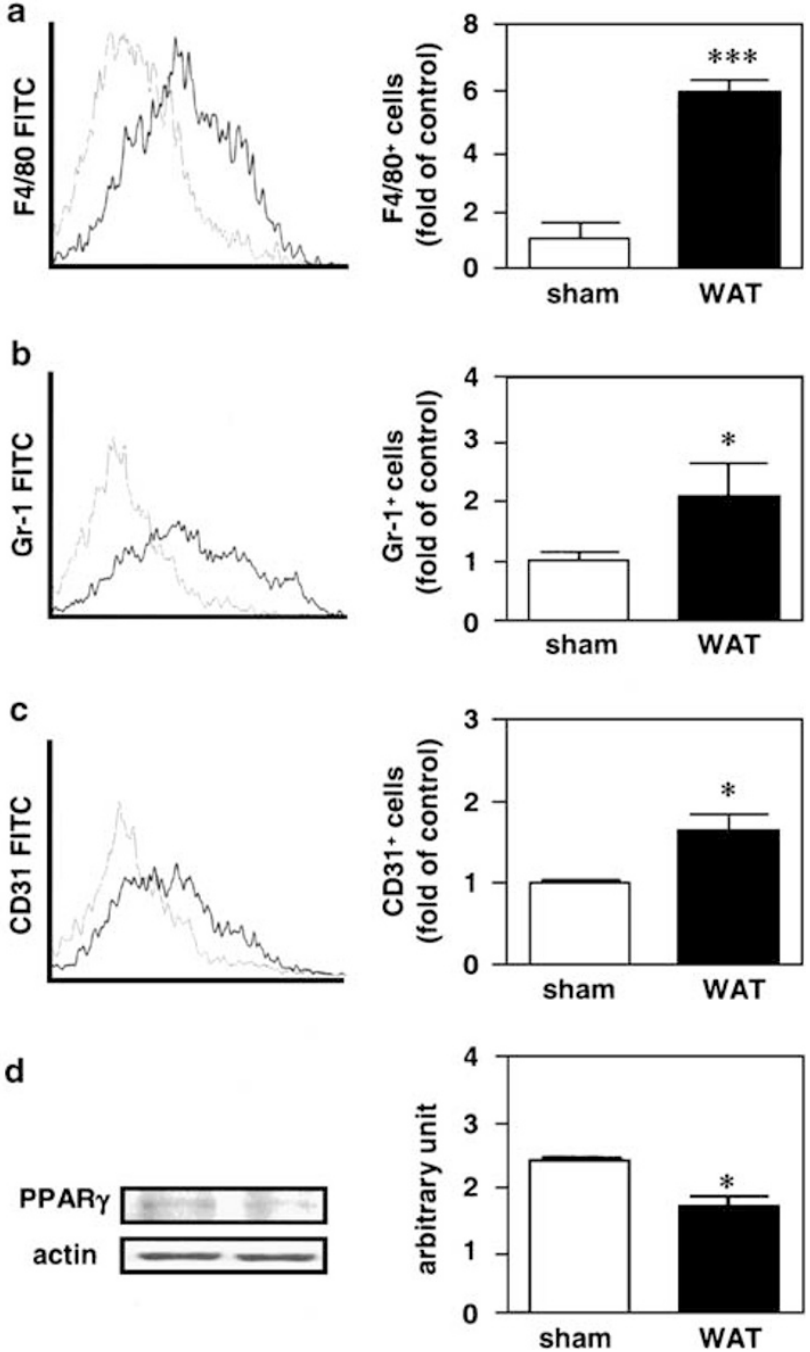

Figure 5 Cotton pellets implanted in the epididymal white adipose tissue (WAT) and interscapular brown adipose tissue (BAT) of BALB/c male mice induced macrophage and neutrophil infiltration, elevated angiogenesis, and reduced PPAR $\gamma$ expression in WAT group mice. Immune cells were obtained from the stromal-vascular fraction in WAT, and stained with antibodies: F4/80 (a), Gr-1 (b), and CD31 (c). The cell subpopulations were quantitated using flow cytometry. Data are mean ( \pm s.e.m.) of the averages from three experiments. (d) PPAR $\gamma$ expression levels in WAT group mice were detected using western blotting. Data are ratios of each protein to actin, which was an internal control and are mean ( \pm s.e.m.) of the averages from four experiments. ${ }^{*} P<0.05,{ }^{*} P<00.01$, and ${ }^{* * *} P<0.001$ compared with the sham group.

investigated as a promising therapeutic target for type 2 diabetes, metabolic syndrome, and cardiovascular disease. ${ }^{41}$ We found that the adiponectin level in the WAT group was much lower than in the BAT group. Thus, decreased adiponectin levels in circulation may accelerate the development of insulin resistance. On the other hand, PPAR $\gamma$ is an essential factor for decreasing macrophage activation ${ }^{42}$ and inflammatory cytokines production. ${ }^{43}$ Its agonists increase adiponectin secretion in cell lines, animal models, and humans. ${ }^{44}$ We found that the levels of PPAR $\gamma$ in adipose tissue 
and adiponectin in circulation had both decreased after the cotton pellets had been implanted in WAT, and that both their protective functions had been impaired. Taken together, the depot-dependent variability, differential sensitivity to inflammation, and altered levels of adiponectin between WAT and BAT with granuloma formation might explain the induction of insulin resistance.

Adipose tissue releases abnormal amounts of adipokines to activate the immune response for the development of insulin resistance in obese individuals. ${ }^{45}$ However, more than $60 \%$ of patients with type 2 diabetes are obese in developed countries; lean noninsulin-dependent diabetes mellitus (a body mass index $<18.5)$ is prevalent in developing countries. ${ }^{46,47}$ Some animal models of insulin resistance without obesity have been established. Animals lacking adequate adipose tissue stores, such as homozygous Akt2 knockout mice, are insulin resistant, but they have reduced adipose tissue mass. ${ }^{48}$ A prolonged infusion of recombinant TNF- $\alpha$ for $24 \mathrm{~h}$ in rats produces hepatic or peripheral insulin resistance without altering body weight. ${ }^{49}$ Furthermore, homozygous IRS-2 deficient mice ${ }^{50}$ and heterozygous for a null allele of the $\mathrm{IR}^{51}$ are insulin resistant without obesity. We established, in this study, an insulin resistant animal model related to inflammation in nonobese mice, which is consistent with other reports that obesity may not be essential for developing insulin resistance. ${ }^{4-51}$ Our present findings also indicated that implanting cotton pellets in WAT may increase the infiltration of immune cells into adipose tissue, as well as downregulate PPAR $\gamma$ expression in WAT, which leads lower levels of adiponectin and acceleration of the development of insulin resistance in mice.

\section{ACKNOWLEDGEMENTS}

We appreciate Miss MJ Wang for the research assistance. We thank Professor YS Lin (Department of Microbiology and Immunology, National Cheng Kung University, Tainan City, Taiwan, ROC) for kindly providing us the antibodies. This work was supported in part by Grant NSC 96-2320-B006010 from the National Science Council, Taiwan. We also thank Bill Franke for editorial assistance.

1. Bays HE, Gonzalez-Campoy JM, Bray GA, et al. Pathogenic potential of adipose tissue and metabolic consequences of adipocyte hypertrophy and increased visceral adiposity. Expert Rev Cardiovasc Ther 2008;6:343-368.

2. Nieves DJ, Cnop M, Retzlaff B, et al. The atherogenic lipoprotein profile associated with obesity and insulin resistance is largely attributable to intra-abdominal fat. Diabetes 2003;52:172-179.

3. Chen H. Cellular inflammatory responses: novel insights for obesity and insulin resistance. Pharmacol Res 2006;53:469-477.

4. Weisberg SP, McCann D, Desai M, et al. Obesity is associated with macrophage accumulation in adipose tissue. J Clin Invest 2003;112:1796-1808.

5. Meyers MR, Gokce N. Endothelial dysfunction in obesity: etiological role in atherosclerosis. Curr Opin Endocrinol Diabetes Obes 2007;14:365-369.

6. Fasshauer M, Paschke R. Regulation of adipocytokines and insulin resistance. Diabetologia 2003;46:1594-1603.

7. Kolb $\mathrm{H}$, Mandrup-Poulsen T. An immune origin of type 2 diabetes? Diabetologia 2005;48:1038-1050.

8. Shoelson SE, Lee J, Goldfine AB. Inflammation and insulin resistance. J Clin Invest 2006;116:1793-1801.
9. Kamei N, Tobe K, Suzuki R, et al. Overexpression of monocyte chemoattractant protein-1 in adipose tissues causes macrophage recruitment and insulin resistance. J Biol Chem 2006;281:26602-26614.

10. Kristiansen OP, Mandrup-Poulsen T. Interleukin- 6 and diabetes: the good, the bad, or the indifferent? Diabetes 2005;54(Suppl 2): S114-S124.

11. Gonzalez-Gay MA, Gonzalez-Juanatey C, Martin J. Rheumatoid arthritis: a disease associated with accelerated atherogenesis. Semin Arthritis Rheum 2005;35:8-17.

12. Morley JE, Thomas DR, Wilson MM. Cachexia: pathophysiology and clinical relevance. Am J Clin Nutr 2006;83:735-743.

13. Anderson JM, Rodriguez A, Chang DT. Foreign body reaction to biomaterials. Semin Immunol 2008;20:86-100.

14. Rao CV, Verma AR, Gupta PK, et al. Anti-inflammatory and antinociceptive activities of Fumaria indica whole plant extract in experimental animals. Acta Pharm 2007;57:491-498.

15. Gupta M, Mazumder UK, Kumar RS, et al. Anti-inflammatory, analgesic and antipyretic effects of methanol extract from Bauhinia racemosa stem bark in animal models. J Ethnopharmacol 2005;98:267-273.

16. Tzeng TF, Lo CY, Cheng JT, et al. Activation of mu-opioid receptors improves insulin sensitivity in obese Zucker rats. Life Sci 2007;80: 1508-1516.

17. Matthews DR, Hosker JP, Rudenski AS, et al. Homeostasis model assessment: insulin resistance and beta-cell function from fasting plasma glucose and insulin concentrations in man. Diabetologia 1985;28:412-419.

18. Ozaki Y, Sakaguchi I, Tujimura M, et al. Study of the accelerating effect of shikonin and alkannin on the proliferation of granulation tissue in rats. Biol Pharm Bull 1998;21:366-370.

19. Bird J, Lay JC, Lee HJ. The effects of new local anti-inflammatory steroids on leucocyte migration and prostanoid liberation in rats. J Pharm Pharmacol 1986;38:589-594.

20. Kapu SD, Ngwai YB, Kayode O, et al. Anti-inflammatory, analgesic and anti-lymphocytic activities of the aqueous extract of Crinum giganteum. J Ethnopharmacol 2001;78:7-13.

21. Hatanaka E, Monteagudo PT, Marrocos MS, et al. Neutrophils and monocytes as potentially important sources of proinflammatory cytokines in diabetes. Clin Exp Immunol 2006;146:443-447.

22. Plomgaard $P$, Nielsen $A R$, Fischer $C P$, et al. Associations between insulin resistance and TNF-alpha in plasma, skeletal muscle and adipose tissue in humans with and without type 2 diabetes. Diabetologia 2007;50:2562-2571.

23. Krol E, Agueel $R$, Banue $S$, et al. Amlodipine reverses the elevation in $\left[\mathrm{Ca}^{2+}\right]_{i}$ and the impairment of phagocytosis in PMNLs of NIDDM patients. Kidney Int 2003;64:2188-2195.

24. Waltenberger J, Lange J, Kranz A. Vascular endothelial growth factor-Ainduced chemotaxis of monocytes is attenuated in patients with diabetes mellitus: a potential predictor for the individual capacity to develop collaterals. Circulation 2000;102:185-190.

25. Katz S, Klein B, Elian I, et al. Phagocytotic activity of monocytes from diabetic patients. Diabetes Care 1983;6:479-482.

26. Yang $Q$, Graham TE, Mody N, et al. Serum retinol binding protein 4 contributes to insulin resistance in obesity and type 2 diabetes. Nature 2005;436:356-362.

27. Steppan CM, Bailey ST, Bhat S, et al. The hormone resistin links obesity to diabetes. Nature 2001;409:307-312.

28. Utzschneider KM, Carr DB, Tong J, et al. Resistin is not associated with insulin sensitivity or the metabolic syndrome in humans. Diabetologia 2005;48:2330-2333.

29. Gomez-Ambrosi J, Rodriguez A, Catalan V, et al. Serum retinol-binding protein 4 is not increased in obesity or obesity-associated type 2 diabetes mellitus, but is reduced after relevant reductions in body fat following gastric bypass. Clin Endocrinol (Oxf) 2008;69:208-215.

30. Gesta S, Tseng YH, Kahn CR. Developmental origin of fat: tracking obesity to its source. Cell 2007;131:242-256.

31. Klaus S, Keijer J. Gene expression profiling of adipose tissue: individual, depot-dependent, and sex-dependent variabilities. Nutrition 2004;20:115-120.

32. Cannon B, Nedergaard J. Brown adipose tissue: function and physiological significance. Physiol Rev 2004;84:277-359.

33. Villena JA, Cousin B, Penicaud L, et al. Adipose tissues display differential phagocytic and microbicidal activities depending on their localization. Int J Obes Relat Metab Disord 2001;25:1275-1280. 
34. Ukkola O, Santaniemi M. Adiponectin: a link between excess adiposity and associated comorbidities? J Mol Med 2002;80: 696-702.

35. Hulthe J, Hulten LM, Fagerberg B. Low adipocyte-derived plasma protein adiponectin concentrations are associated with the metabolic syndrome and small dense low-density lipoprotein particles: atherosclerosis and insulin resistance study. Metabolism 2003;52: 1612-1614.

36. Lafontan M, Viguerie $\mathrm{N}$. Role of adipokines in the control of energy metabolism: focus on adiponectin. Curr Opin Pharmacol 2006; 6:580-585.

37. Fujimoto $\mathrm{N}$, Matsuo $\mathrm{N}$, Sumiyoshi $\mathrm{H}$, et al. Adiponectin is expressed in the brown adipose tissue and surrounding immature tissues in mouse embryos. Biochim Biophys Acta 2005;1731:1-12.

38. Kim JY, van de Wall E, Laplante $M$, et al. Obesity-associated improvements in metabolic profile through expansion of adipose tissue. J Clin Invest 2007;117:2621-2637.

39. Lin HV, Kim JY, Pocai A, et al. Adiponectin resistance exacerbates insulin resistance in insulin receptor transgenic/knockout mice. Diabetes 2007;56:1969-1976.

40. Ryo M, Nakamura T, Kihara S, et al. Adiponectin as a biomarker of the metabolic syndrome. Circ J 2004;68:975-981.

41. Kadowaki T, Yamauchi T. Adiponectin and adiponectin receptors. Endocr Rev 2005;26:439-451.

42. Ricote $M$, Huang J, Fajas $L$, et al. Expression of the peroxisome proliferator-activated receptor gamma (PPARgamma) in human atherosclerosis and regulation in macrophages by colony stimulating factors and oxidized low density lipoprotein. Proc Natl Acad Sci USA 1998;95:7614-7619.

43. Jiang C, Ting AT, Seed B. PPAR-gamma agonists inhibit production of monocyte inflammatory cytokines. Nature 1998;391:82-86.

44. Hammarstedt A, Andersson CX, Rotter Sopasakis V, et al. The effect of PPARgamma ligands on the adipose tissue in insulin resistance. Prostaglandins Leukot Essent Fatty Acids 2005;73:65-75.

45. Bastard JP, Maachi M, Lagathu C, et al. Recent advances in the relationship between obesity, inflammation, and insulin resistance. Eur Cytokine Netw 2006;17:4-12.

46. Mohan V, Vijayaprabha R, Rema M, et al. Clinical profile of lean NIDDM in south India. Diabetes Res Clin Pract 1997;38:101-108.

47. Ramachandran A, Jali MV, Mohan V, et al. High prevalence of diabetes in an urban population in south India. BMJ 1988;297:587-590.

48. Garofalo RS, Orena SJ, Rafidi K, et al. Severe diabetes, age-dependent loss of adipose tissue, and mild growth deficiency in mice lacking Akt2/PKB beta. J Clin Invest 2003;112:197-208.

49. Lang $\mathrm{CH}$, Dobrescu C, Bagby GJ. Tumor necrosis factor impairs insulin action on peripheral glucose disposal and hepatic glucose output. Endocrinology 1992;130:43-52.

50. Kubota N, Tobe K, Terauchi Y, et al. Disruption of insulin receptor substrate 2 causes type 2 diabetes because of liver insulin resistance and lack of compensatory beta-cell hyperplasia. Diabetes 2000;49:1880-1889.

51. Bruning JC, Winnay J, Bonner-Weir S, et al. Development of a novel polygenic model of NIDDM in mice heterozygous for IR and IRS-1 null alleles. Cell 1997:88:561-572. 